\title{
PROSPECCIÓN E IDENTIFICACIÓN DE AISLADOS DE Phytophthora infestans EN EL NORTE DE ESPAÑA
}

\author{
PROSPECTING AND IDENTIFICATION OF ISOLATES OF Phytophthora \\ infestans IN NORTHERN SPAIN
}

\author{
${ }^{1}$ Néstor Alor ; ${ }^{2}$ Isidra Gutierrez; ${ }^{3}$ José Ignacio Ruiz de Galarreta
}

\begin{abstract}
RESUMEN
El Oomycete Phytophthora infestans (Mont.) de Bary, especie de distribución mundial, es una amenaza para la seguridad alimentaria mundial. En los últimos años en España se ha detectado una mayor agresividad de esta enfermedad debido a las variaciones genéticas del patógeno, y causando importantes pérdidas en la producción de patata y tomate. El objetivo fue realizar una prospección e identificación del tipo de apareamiento en 5 aislados P. infestans en Alava (País Vasco, Norte de España). Para ello, se realizó una caracterización fenotípica mediante cruzamientos In vitro con cepas de referencia de tipo sexual conocido A1 y A2. Posteriormente se caracterizaron genotipicamente mediante marcadores moleculares especificos, tipo CAPS. Los resultados mostraron que los aislados Gau-1301, Her-1301 y Zua-1301 pertenecen al tipo de apareamiento Al, y los aislados Itu-1203 y Ark-1301 al tipo de apareamiento A2.
\end{abstract}

Palabras Clave: CAPS, caracterización fenotipica, caracterización genética, marcadores moleculares, tipo de apareamiento.

ABSTRACT

The Oomycete Phytophthora infestans (Mont.) de Bary, a worldwide species, it is a threat to the global food security. In recent years, in Spain has detected an increase in the aggressiveness of the disease by the genetic variation, causing severe losses in the crop production, like potato and tomato. The aim of this study was the prospecting and identification of mating type in five isolates of P. infestans from Alava (Basque Country, North of Spain). Their phenotype was characterized by In vitro crossing, with reference strains, sexual type knowns A1 and A2. After it did a genotypic characterization by molecular markers, CAPS. The results showed GAU-1301, Her-1301 and ZUA-1301 isolated were mating type Al, and Itu-1203 y Ark-1301 mating type A2.

Key words: CAPS, phenotypic characterization, genetic characterization, molecular markers, mating type

\section{INTRODUCCIÓN}

\section{Epidemiología del mildiu}

El Oomycete Phytophthora infestans (Mont.) de Bary, es una especie de distribución mundial, causante del tizón tardío o mildiu, una de las enfermedades más limitantes y devastadoras de la patata $(S$. tuberosum $\mathrm{L}$.), aunque también puede afectar a otras Solanáceas, como el tomate y el pepino. Las condiciones ambientales óptimas para el desarrollo de la enfermedad se encuentran por encima de $\operatorname{los} 10^{\circ} \mathrm{C}$ y una humedad relativa del $90 \%$

Según estimaciones del Centro Internacional de la Papa, Lima (Perú), el mildiu reduce aproximadamente un $15 \%$ la producción mundial de patata y las cuantiosas pérdidas económicas, cifradas en más de 1000 millones de euros tan sólo en Europa, a todo esto debemos sumar el impacto medioambiental y en la salud humana, por el uso de fungicidas para el control de la enfermedad.
Este patógeno presenta dos tipos de reproducción: sexual y asexual.

Para la reproducción sexual se comporta como una especie heterotálica, es decir, necesita la existencia de dos tipos de razas con tipos de apareamiento diferente $(A 1 \mathrm{y}$ A2). La unión de los anteridios (gametos masculinos) y oogonios (gametos femeninos), produce una oospora diploide, la cual por recombinación genética puede generar una mayor variabilidad en patogenicidad y agresividad. La formación de estas oosporas le permite a $P$. infestans sobrevivir en condiciones adversas del invierno, períodos secos y ausencia de hospedantes durante meses o incluso años.

Por su parte, la reproducción asexual, se produce a través de los esporangios, zoosporas e hifas. Las zoosporas se forman dentro de los esporangios y cuando son liberados se enquistan sobre superficies de las hojas, y en presencia de humedad, pueden desarrollar un tubo germinativo y

Student Ph. D . Cienciay Teenologia Agraria y Alimentaria. Msc. Mejora Genética Vegetal. Ingeniero Agrónomo(UNJBG). Departamento de Producciỏn y Proteceión Vegetal. Instituto Vasce de Investigación y Desarrollo Agranio-Neiker Tectualia. España.

Técnico Analista del Laboratorio In Vitro, Instituto Vasco de Investigación y Desarrollo Agrario-Neiker Teenalia. España

PhD Biologia, Investigador Principal. Departamento de Producción y Protección Vegetal. Instítuto Vasco de Investigación y Desarrollo Agrario-Neiker Tecnalia. España. 


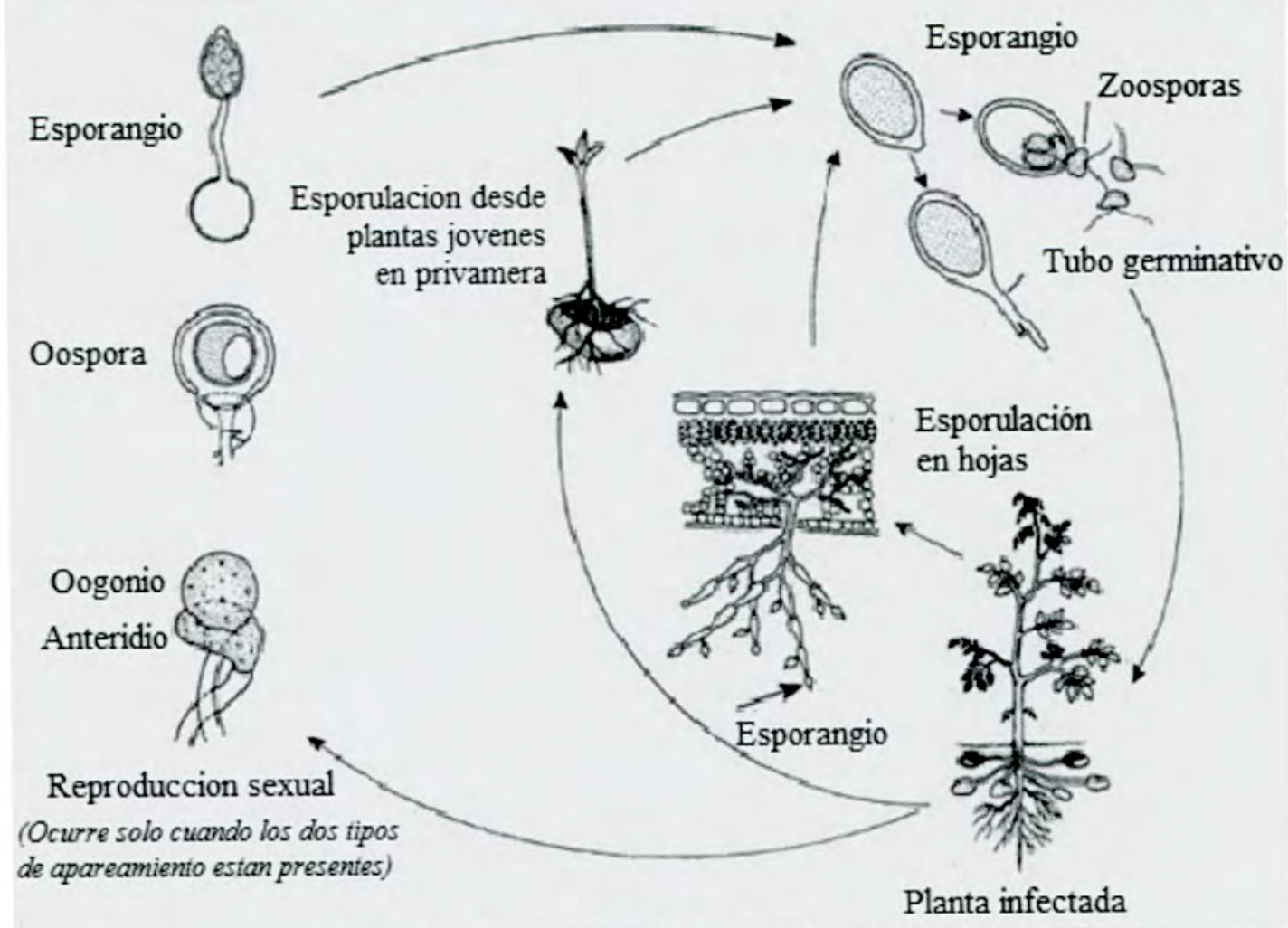

Figura $\mathrm{N}^{\circ} 01$. Ciclo biológico del mildiu de la patata (Schumann y D'arcy)

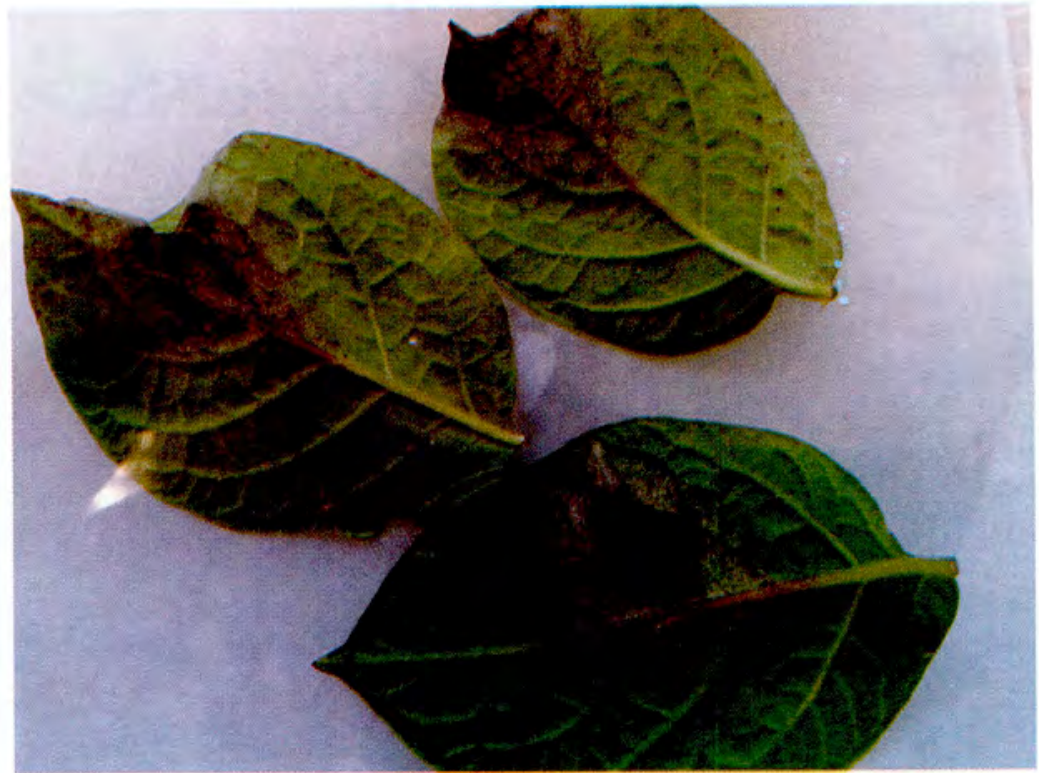

Figura $\mathrm{N}^{\circ} 02$. Daños ocasionados por el mildiu en hoja.

penetrar a través de los estomas.

\section{MATERIALES Y MÉTODO}

\section{Zonas prospectadas en la provincia de Álava}

En los últimos años se han detectado en Europa grandes cambios en las poblaciones de Pbytophthora infestans, reflejando una mayor virulencia y agresividad, dificultando notablemente el manejo de la enfermedad por su resistencia a los fungicidas actualmente utilizados. Por ello se hace necesaria una prospección y caracterización del patógeno con el fin de conocer el tipo de razas que existen en nuestra geografía para poder optimizar la eficacia de los métodos de control.

De esta forma, se planteó el presente trabajo con el objetivo de caracterizar fenotípicamente y genéticamente un conjunto de aislados de $P$. infestans recolectados durante los meses de Julio-Agosto del 2013, en cultivos de patata que fueron atacados por el mildiu en distintas localizaciones geográficas productoras de patata de Álava como Arkaute, 
Tabla $\mathrm{N}^{\circ} 01$. Aislados de $P$. infestans prospectados en

\begin{tabular}{lllll}
\hline Aislados & Fecha & Variedad Localidad & Comarca \\
\hline Ark-1301 & $30 / 07 / 2013$ & Spunta & Arkaute & Llanada alavesa \\
Gau-1301 & $27 / 08 / 2013$ & Agria & Gauna & Llanada alavesa \\
Her-1301 & $27 / 08 / 2013$ & Desiree & Heredia & Llanada alavesa \\
Zua-1301 & $27 / 08 / 2013$ & Monalisa & Zuazo de San Millán Llanada alavesa \\
Itu-1203 & $27 / 08 / 2013$ & Gorbea & Iturrieta & Montaña \\
\hline
\end{tabular}

Gauna, Heredia, Zuazo de San Millán e Iturrieta (Tabla $\mathrm{N}^{\circ} 01$ ).

\section{RESULTADOS Y DISCUSIÓN}

\section{Caracterización fenotípica de $P$. infestans}

Se determinó el tipo de apareamiento mediante cruzamiento in vitro. Para ello se inocularon los aislados con las cepas de referencia del tipo sexual conocido $A 1$ ó $A 2$ de $P$. infestans, en medio de cultivo Agar-centeno (Tooley et al., 1989). Las placas se incubaron durante 15 días a $18^{\circ} \mathrm{C}$ y en total oscuridad. Transcurrido dicho periodo, se observaron las placas al microscopio para determinar la presencia o ausencia de oosporas. Los aislamientos que formaron oosporas con la cepa de referencia del tipo $A 1$ se les identificó como $A 2$, mientras que los que produjeron oosporas con la cepa de referencia $A 2$ se les identificó como A1.

Como controles del tipo de apareamiento en las pruebas de caracterización fenotípica se emplearon dos cepas de referencia conocidas (Tabla $\mathrm{N}^{\circ} 02$ ). Así, para el tipo de apareamiento $A 1$ se utilizó la cepa MP-324 procedente de Polonia del Instituto Polaco de Fitomejoramiento y
Tabla $\mathrm{N}^{\circ} 02$. Cepas de referencia empleadas en el

\begin{tabular}{ccc}
\hline Especie & Tipo de apareamiento & Cepa \\
\hline P. infestans & $A 1$ & MP-324 \\
& $A 2$ & R1-A2 \\
\hline
\end{tabular}

Aclimatación Vegetal (IHAR) y como control de $A 2$ la cepa RI-A2 previamente caracterizada, y proporcionada por la Universidad Queen's de Belfast (Irlanda del Norte).

Los resultados mostraron que los aislados Gau1301, Her-1301 y Zua-1301 correspondían con el tipo de apareamiento $A 1$ ya que al ser observados al microscopio se detectaron oosporas tras el cruzamiento con la cepa de referencia R1-A2 (A2). Por otro lado, los aislados Itu-1203 y Ark-1301 fueron identificados con el tipo de apareamiento A2 ya que se observó la presencia de oosporas tras el cruzamiento con la cepa de referencia MP-324 de tipo de apareamiento $A 1$.

\section{Caracterización genética de $P$. infestans}

El método fenotípico antes descrito es la forma inicial para determinar el tipo de apareamiento mediante el cruzamiento in vitro con cepas de referencia, pero dichos resultados, actualmente, se pueden certificar con el empleo de técnicas moleculares.

El método consistió en la extracción del ADN de los aislados para posteriormente aplicar la técnica PCR (Polymerase Chain Reaction). Esta se llevó a cabo con cebadores o iniciadores para marcadores CAPS (Cleaved Amplified Polymorpbic Sequence) de P. infestan. Se empleó, asimismo, un control interno de la reacción con agua destilada, así como testigos de las cepas de referencia de cada tipo de apareamiento, anteriormente mencionadas.

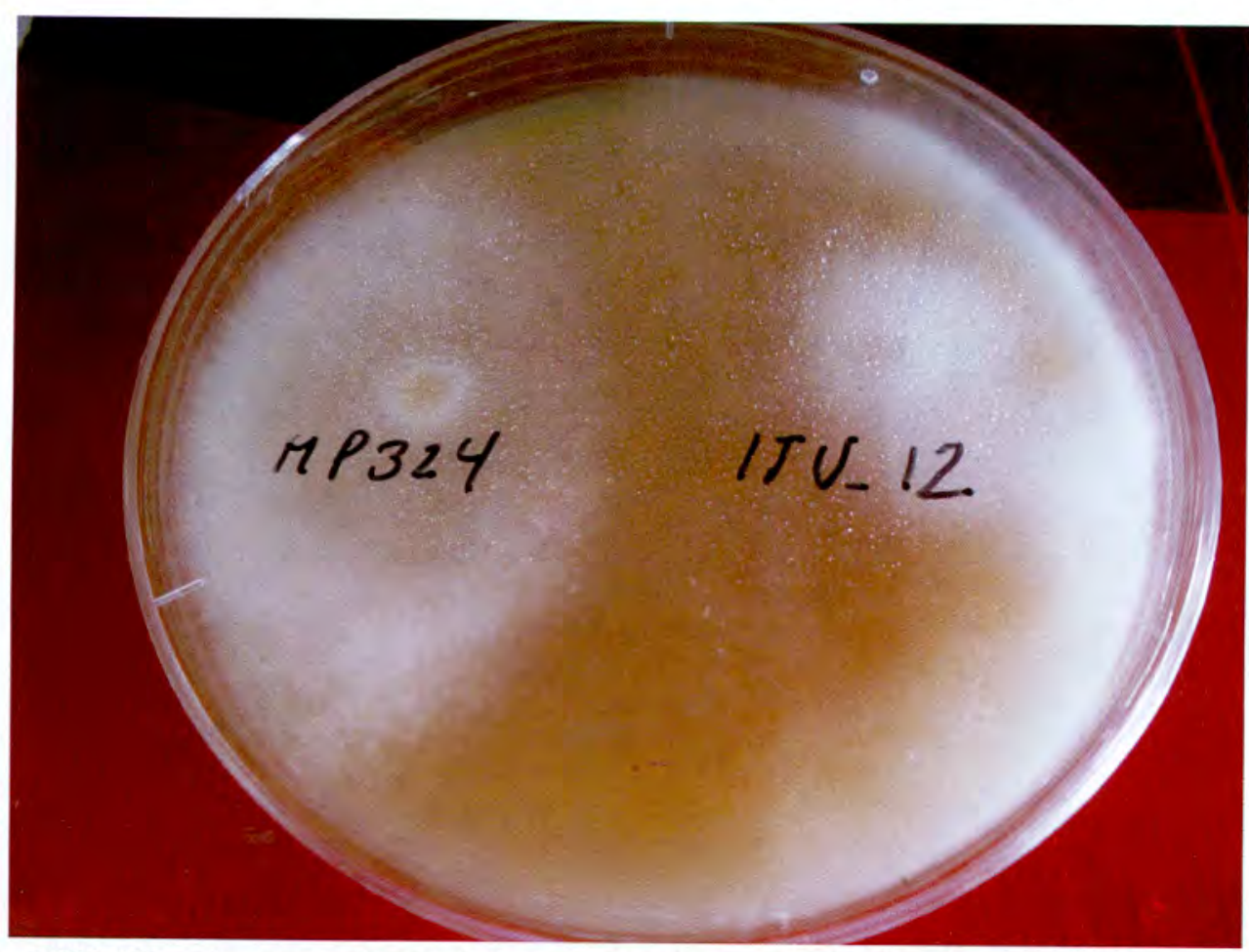

Figura No03. Tipo de apareamiento de la cepa de referencia MP324 (A1) con el aislado ITU-1203. 


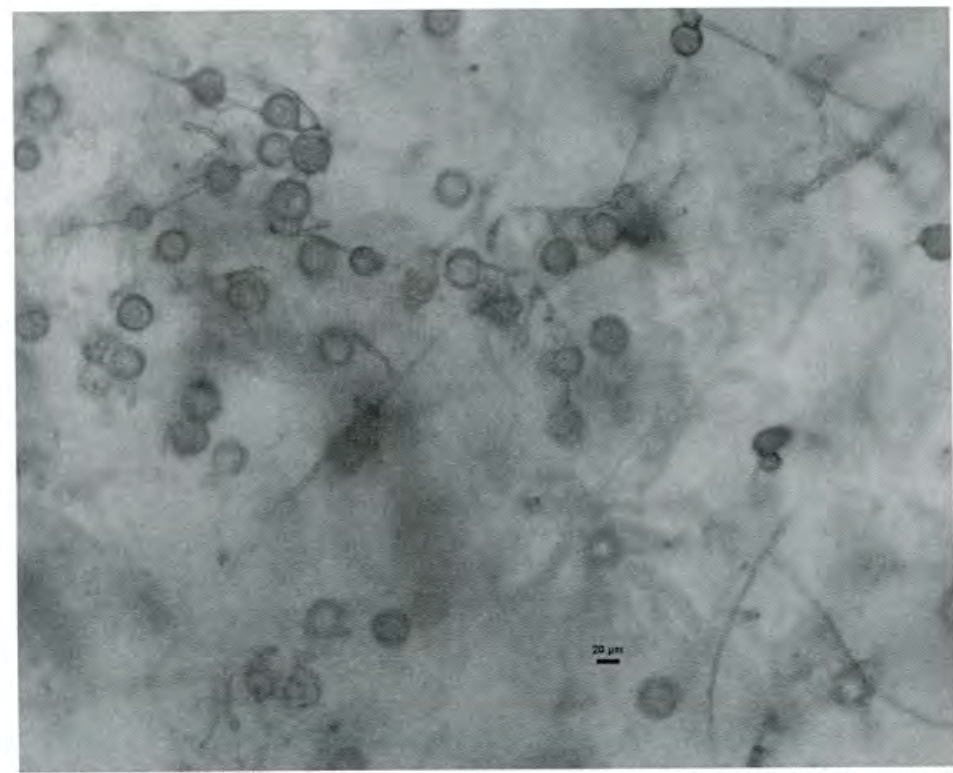

Figura $\mathrm{N}^{\circ} 04$. Formación de oosporas entre la cepa de referencia MP-324 (A1) y el aislado ITU-1203 (A2).

Para la extracción del ADN se utilizaron placas Petri conteniendo el medio de Agar-centeno en el que fue cultivado el aislado. Se procedió a realizar un raspado en la superficie del micelio previamente humedecido con $4 \mathrm{ml}$ de agua estéril, todo esto bajo condiciones asépticas, trabajando para ello en cámara de flujo vertical. Una vez obtenido el micelio se liofilizó por 24 horas para facilitar la posterior homogenización del tejido. Después de ello se realizó una disgregación mecánica del tejido liofilizado, empleando nitrógeno líquido. A continuación se procedió a extraer el ADN de los aislados y de las cepas de referencia $A 1$ y $A 2$, con el kit comercial DNeasy Plant Mini Kit de Qiagen ${ }^{*}$.

Para la identificación de los patrones característicos de cada aislado, se amplificó el material genético utilizando los cebadores W16-1 y W16-2, que permiten amplificar un fragmento inicial de $600 \mathrm{pb}$ que es necesario digerir para poder identificar los dos tipos de apareamiento (Judelson et al., 1995). Tras esta digestión con el enzima de restricción rápida HaeIII, se realizó la visualización mediante fluorescencia en Chemidocx XRS del gel de agarosa al 1\%, el cual permite distinguir los dos tipos de apareamiento de $P$. infestans $A 1$ y $A 2$.

El tipo de apareamiento $A 1$ muestra tres bandas patrón con un tamaño molecular de 600,550 y 50 pb, mientras que para el tipo de apareamiento $A 2$ presenta dos fragmentos de restricción con bandas de tamaño molecular

Tabla $N^{\circ} 03$. Cebadores utilizados en la PCR para marcadores CAPS.

\begin{tabular}{|c|c|c|c|}
\hline Cebador & Secuencia de nucleótidos & Fragmento inicial en A1 y A2 & Fragmentos tras la digestión \\
\hline W16-1 & 5'- AAC ACG CAC AAG GCA TAT AAA TCT A- 3' & $600 \mathrm{pb}$ & $\begin{array}{l}\text { A1: } 3 \text { bandas } \\
(600,550,50) \mathrm{pb}\end{array}$ \\
\hline W16-2 & 5'- GCG TAA TGT AGC GTA ACA GCT CTC- 3' & & $\begin{array}{c}\text { A2: } 2 \text { bandas } \\
(550,50) \mathrm{pb}\end{array}$ \\
\hline
\end{tabular}

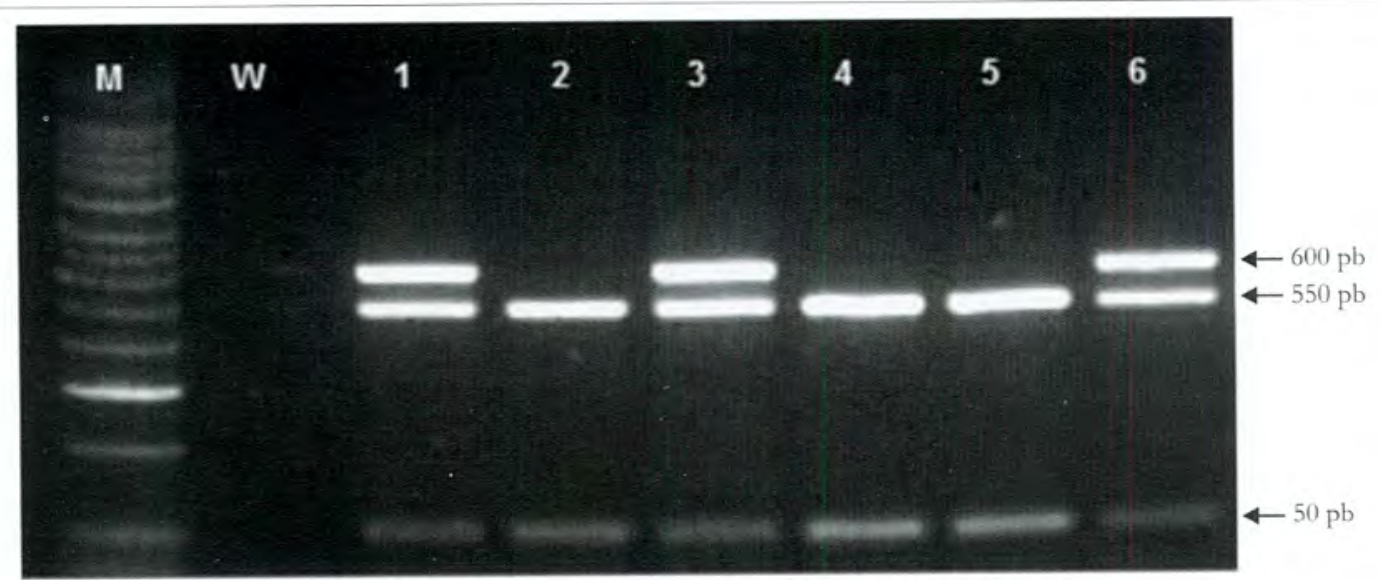

Figura $\mathrm{N}^{\circ}$ 05. Patrones moleculares identificados como tipos de apareamiento A1 y A2.

Fragmentos obtenidos mediante la técnica CAPs. M: Marcador de peso molecular. W: Control interno (agua). Muestras del 1 al 6: Cepas A1 y A2 de P. infestans tras la digestión. 
de 550 y $50 \mathrm{pb}$. (Tabla N $\left.{ }^{\circ} 03\right)$.

Los resultados obtenidos mostraron que los aislados Ark-1301 y Itu-1203 pertenecen al tipo de apareamiento $A 2$, ya que mostraron dos bandas con un tamaño molecular de 550 y $50 \mathrm{pb}$, respectivamente. Dichas bandas patrón se corresponden con el tipo del apareamiento A2. Del mismo modo, los aislados Gau-1301, Her-1301 y Zua-1301 fueron identificados como $A 1$, al presentar tres bandas de tamaño 600,550 y $50 \mathrm{pb}$, respectivamente, correspondiendo con el tipo de apareamiento $A 1$ (Figura 5).

\section{CONCLUSIONES}

Las implicaciones de los resultados obtenidos en este estudio son de gran importancia en la epidemiología del mildiu. Por primera vez en Álava se han identificado los dos tipos de apareamiento $(A 1$ y $A 2)$ en los aislados estudiados. Esto trae como consecuencia la posibilidad de aparición de reproducción sexual entre los aislados encontrados.

Con ello se aumentaría la variabilidad con nuevas razas del patógeno que dificultarían notablemente el control y manejo de la enfermedad por ser éstas, resistentes a los actuales fungicidas existentes en el mercado. De hecho en los últimos años, se está observando una agresividad inusual no encontrada hasta la fecha y la ruptura de la resistencia a
Alor N. ct al., Prospección c Identificación de aislados de Phytophthora infestans en el norte de Espana determinadas materias activas que se emplean.

El Instituto Neiker continúa con la prospección a nivel nacional, en todas las zonas de producción de patata, para estudiar y caracterizar en profundidad las poblaciones españolas de mildiu y realizar un seguimiento de su evolución. Los resultados que se encuentren, se continuarán publicando con el fin de conocer la situación actual de la enfermedad y poder contribuir más eficazmente a su control.

\section{AGRADECIMIENTOS}

Este trabajo fue financiado en el marco del proyecto INIA RTA2011-00018-C03-01 y por el Gobierno Vasco.

\section{REFERENCIAS BIBLIOGRÁFICAS}

Judelson, H.S., Spilman, L.J. \& Shattock, R.C. 1995. Genetic mapping and non-Mendelian segregation of mating type loci in the oomycete Phytophthora infestans. Genetics. 141: 503-512.

Tooley P.W., Therrien C.D., Ritch D.L. 1989. Mating type, race composition, nuclear DNA content, and isozyme analysis of Peruvian isolates of Phytophthora infestans. Phytopathology. 79: 478-481.

\section{Correspondencia:}

Néstor Alor: nalor@neiker.net
Fecha de Recepción: 01/07/2014

Fecha de Aceptación: 09/07/2014 